\title{
Study on Ultimate State and Mechanical Characteristics of Connection Joint of Damaged H-Shaped Bracing Structure
}

\author{
Yonezawa Yasuto*, Kenta Aoki, Takumi Ito and Changhoon Choi
}

Department of Architecture, Tokyo University of Science, Tokyo, Japan

\begin{abstract}
In Japan, various kinds of failure modes in steel structures have been reported in severe past earthquake disasters. Also, the various type of repair method for damaged building structure is suggested, and it has been published as restoration manual and guideline. However, it is guessed that these repair methods have some difficulties related to construction technique and estimation of recovery of seismic resistant performance after repair. This study focuses on the seismic ultimate state of steel brace connection of original state and repaired state after damaged, and the effective restoration method is suggested herein. In our past researches, new repairing method for damaged steel bracing joint which has angle-section brace member has been suggested already, and its applicability and feasibility were investigated experimentally. Herein, $\mathrm{H}$ - shaped section brace members are focused which are adopted on middle-rise or high-rise steel building structures, and also, various kinds of failure modes of these bracing structure has been reported after past terrible seismic disasters in Japan. So, the effective restoration method is proposed here. First, to reproduce the seismic ultimate state, the vertical loading test on $\mathrm{H}$-shaped bracing test specimen are performed as parameters with bolt layout, thickness of gusset plate, that is, out-of-plane rigidity of joint. Next, the damaged bracing joints are repaired. Finally, the loading test is done on repaired specimen again. From test results, the restoring force characteristics after repair can be recovered, and any type of failure modes are observed. So, 3D model of damaged bracing joint is constructed by using 3D scanner, and it helps to identify the failure mode and yield lines on gusset plate. Furthermore, the plastic limit analysis is performed by reference of $3 \mathrm{D}$ model, and it can predict the ultimate state of test results well.
\end{abstract}

Keywords: Steel braced structure; Repair method; Gusset plate

\section{Introduction}

Recently, a lot of building are damaged variously after huge earthquake disasters, and it is necessary to decide whether they are rebuilt or reuse [1]. The steel frame structures are roughly classified into rahmen framework or braced structure, and serious damages are reported to both of them. And from these experiences, a new keyword such as "Resilience" is noticed, which means revival potential or functional maintenance of damaged structure [2]. From the viewpoint of reconstruction and restoration of the city function promptly, it is desirable to repair and reuse the public buildings which become the base of recover and reconstruction in the stricken area in Japan. Also, these public buildings are mainly braced structure, and which are many reports as follows; the various types of failure modes of steel braced structure, such as buckling, fracture of brace member, and yielding of joints and fasteners as shown in Figure 1 [3]. When these damages are occurred, the seismic resistant performance is enormously deteriorated, and the unstable behavior is appeared. In japan, the diagnosis methods for these failure modes are discussed in the technical guideline [1]. Furthermore, the guideline suggests some actual repair methods, however, the suitable method considering the state of stricken area are required.

In this study, in case of damaged gusset plate of bracing joints of $\mathrm{H}$-shaped bracing member, the effective repair method is suggested. In addition, the horizontally loading tests are conducted to investigate the effectivity and its seismic resistant performance. Finally, it aims to propose an evaluation method of resistant mechanism and restoring force characteristics of repaired state.

\section{General Description of Damaged Steel Braced Frame and Repair Method}

\section{Outline of damaged steel braced frame and after repair}

In this paper, the middle rise or high-rise steel buildings with bracing are focused, and which bracing members are adopted with

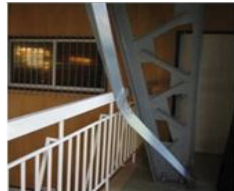

(a)buckling

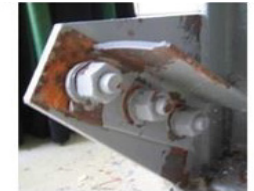

(b)break

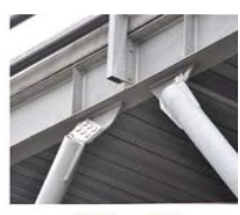

(c)bend
Figure 1: Examples of damaged steel brace members under past seismic disasters in Japan

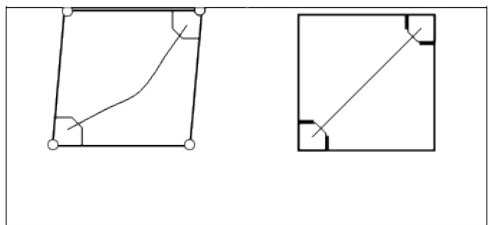

Figure 2: Conceptual image of damaged bracing frame and after repair.

large section steel members such as H-shaped or closed hollow section members. When these steel braced frames are damaged subjected to severe earthquake disasters as shown in Figure 2, the various kind of failure mode were observed as previous mentioned during past seismic disasters in Japan.

*Corresponding author: Yonezawa Yasuto, Department of Architecture Tokyo University of Science, Tokyo, Japan, Tel: +81 3-3260-4271; E-mail: j4113107@gmail.com

Received August 22, 2017; Accepted October 13, 2017; Published October 18 2017

Citation: Yasuto Y, Aoki K, Ito T, Choi C (2017) Study on Ultimate State and Mechanical Characteristics of Connection Joint of Damaged H-Shaped Bracing Structure. J Civil Environ Eng 7: 286. doi: 10.4172/2165-784X.1000286

Copyright: @ 2017 Yasuto Y, et al. This is an open-access article distributed under the terms of the Creative Commons Attribution License, which permits unrestricted use, distribution, and reproduction in any medium, provided the original author and source are credited. 
When these damaged bracing frames are repaired with strengthened members installed, the mechanical resistant state subjected to seismic loading is changed as shown in Figure 3, in which the rigidity of outof-plane of joint and the effective slenderness ratio of brace member is changed. To discuss the repair method on damaged steel braced frames, these effects must be considered whether the seismic resistant performance is changed.

\section{Repair methods of damaged joint of $\mathrm{H}$-shaped bracing member}

This study focuses on the repair method and ultimate resistant mechanism related to the failure mode of joint of $\mathrm{H}$-shaped brace member with out of plane deformation occurrence as shown in Figure 4. It is considered that the following repair processes are necessary (Figure 3 ); the damaged brace and fasteners are changed, and the damaged gusset plate with out of plane deformation occurrence is repaired.

When a new brace member is attached to the damaged gusset plate on this ultimate state, the layout of bolt hole between damaged gusset plate and new brace is deformed with out of position (Figure 5). So then, it is necessary to expand to joint bolt holes precisely.

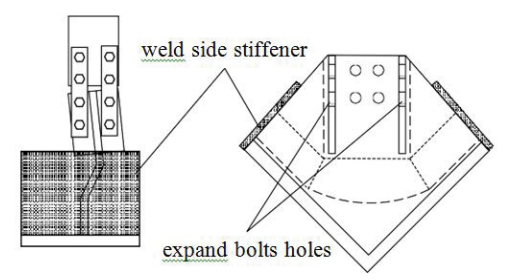

Figure 3: Repair methods of damaged gusset plate.

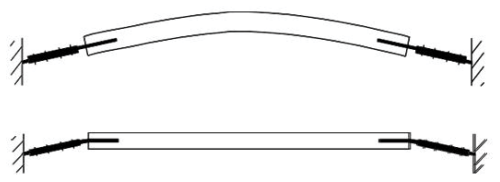

Figure 4: Failure mode of joint of $\mathrm{H}$-shaped brace member.

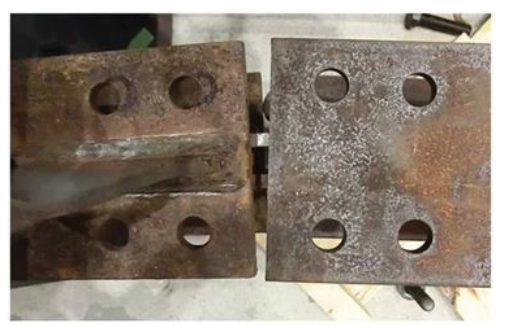

Figure 5: The position of brace and gusset plate.

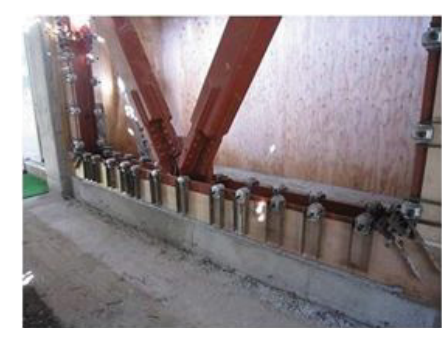

Figure 6: Gusset plate covered mortar.

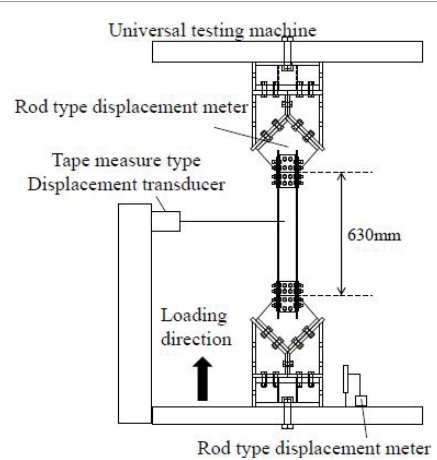

Figure 7: Test setup of axial loading

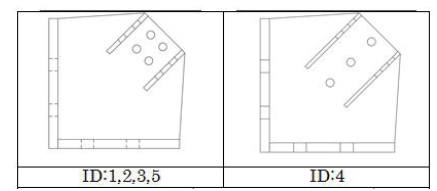

Figure 8: Bolt layout (ID is explained Table 1).

Herein, after the steel member is yield, the rigidity is usually deteriorated. So, it is desirable to be strengthened to recover the restoring force characteristics. Sometimes, it is predicted that it has some difficulties to replace the gusset plate because it is covered with mortar or interior members (Figure 6). So, in this study, the damaged gusset plate is not replaced, and this situation is considered as boundary condition, the stiffener member is attached to prevent the unstable behavior of gusset plate which experiences the yielding.

To summarize the above-mentioned repair process and method, the outline of repair method is as follows: First, the bolt hole on gusset plate is expanded. Next, the side stiffener is welded on the side of gusset plate. The details of proposed repair methods are shown in Figure 3.

\section{Inspection of Repair Effect of H-shaped Brace Member by Compression Loading Test}

\section{Outline of monotonic compression loading test}

In this paper, the compression loading test is performed on the $\mathrm{H}$-shaped brace member to investigate the ultimate state with buckling behavior appearance and repair effect by previous mentioned repair method.

Figure 7 presents the test setup and test specimen which reappears a plane of bracing structure. Both ends of test specimen are supported as fix condition. The procedure of experimental study is as follows:

- $\quad$ First, the monotonic compression loading test is done on original state of test specimen until the ultimate state appearance, and the damage state of brace member is reproduced which was observed under past seismic disasters (herein after referred to as "Initial loading").

- Second, the damaged member is repaired or replaced; in which the damaged gusset plates is repaired, and the brace member is replaced to new member. Finally, the loading test is done to the repair specimen again (herein after referred to as "Second loading").

\section{Experimental variables}

In this paper, the rigidity of out of plane of joint and the slenderness ratio of brace member, and repair state are considered as experimental variables, that is, the rigidity is arranged with the layout of bolts (Figure 
Citation: Yasuto Y, Aoki K, Ito T, Choi C (2017) Study on Ultimate State and Mechanical Characteristics of Connection Joint of Damaged H-Shaped Bracing Structure. J Civil Environ Eng 7: 286. doi: 10.4172/2165-784X.1000286

Page 3 of 6

\begin{tabular}{|c|c|c|c|c|c|c|c|c|}
\hline \multirow{3}{*}{ ID } & \multirow{3}{*}{ Specimen name } & \multirow{3}{*}{ Thickness (mm) } & \multirow{3}{*}{$\begin{array}{l}\text { Fin stiffener length } \\
\qquad(\mathrm{mm})\end{array}$} & \multicolumn{5}{|c|}{ Bolt layout (M12-F10T, JIS standard) } \\
\hline & & & & \multirow{2}{*}{ Side stiffener } & \multicolumn{2}{|c|}{ Array } & \multirow{2}{*}{$\begin{array}{l}\text { End distance } \\
\qquad(\mathrm{mm})\end{array}$} & \multirow{2}{*}{ Pitch (mm) } \\
\hline & & & & & Row & Column & & \\
\hline 1 & H-6-95-S & \multirow{3}{*}{6} & 95 & Existence & \multirow{3}{*}{2} & \multirow{3}{*}{4} & \multirow{3}{*}{20} & \multirow{3}{*}{35} \\
\hline 2 & $\mathrm{H}-6-130-\mathrm{N}$ & & 130 & \multirow{4}{*}{ Non } & & & & \\
\hline 3 & $\mathrm{H}-6-95-\mathrm{N}$ & & 95 & & & & & \\
\hline 4 & $\mathrm{H}-9-130-\mathrm{N}$ & 9 & 130 & & 1 & 6 & \multirow{2}{*}{22} & 50 \\
\hline 5 & $\mathrm{H}-6-120-\mathrm{N}$ & 6 & 120 & & 2 & 4 & & 45 \\
\hline
\end{tabular}

Table 1: List of test specimens and test names.

\begin{tabular}{|c|c|c|c|c|c|c|c|c|}
\hline \multirow{3}{*}{\multicolumn{2}{|c|}{ ID }} & \multirow{3}{*}{ Cross Section of brace members } & \multicolumn{6}{|c|}{ Bolt layout(M12-F10T, JIS standard) } \\
\hline & & & \multicolumn{3}{|c|}{ Web } & \multicolumn{3}{|c|}{ Flange } \\
\hline & & & Array & End distance & Pitch & Array & End distance & Pitch \\
\hline \multicolumn{2}{|c|}{$1 \cdot 2 \cdot 3$} & $\mathrm{H}-100 \times 100 \times 6 \times 8$ & \multirow{2}{*}{2 Row 2 Column } & \multirow{2}{*}{22} & \multirow{2}{*}{30} & \multirow{4}{*}{1 Row 2 Column } & 20 & 35 \\
\hline & 5 & $\mathrm{H}-100 \times 100 \times 4.5 \times 4.5$ & & & & & 22 & 30 \\
\hline \multirow{2}{*}{4} & Edge part & $\mathrm{BH}-100 \times 100 \times 4.5 \times 4.5$ & \multirow{2}{*}{1 Row 3 Column } & \multirow{2}{*}{22} & \multirow{2}{*}{35} & & \multirow{2}{*}{22} & \multirow{2}{*}{30} \\
\hline & Shaft part & $\mathrm{BH}-100 \times 80 \times 4.5 \times 4.5$ & & & & & & \\
\hline
\end{tabular}

Table 2: Properties of steel brace member of brace test specimens.

\begin{tabular}{|c|c|c|c|}
\hline Element & Yield strength (Mpa) & Tensile strength (Mpa) & Yield strain ( $\boldsymbol{\mu})$ \\
\hline Brace-web (ID:1,3,5) & 338 & 449 & 1661 \\
\hline Brace-flange (ID:1,3,5) & 342 & 447 & 1653 \\
\hline Brace (ID:2,4) & 362 & 435 & 203 \\
\hline Gusset plate (ID:1,3,5) & 360 & 421 & 207 \\
\hline Gusset plate (ID:2) & 353 & 467 & 1736 \\
\hline Gusset plate(ID:4) & 370 & 419 & 1683 \\
\hline Fin stiffener (ID:1,3,5) & 253 & 475 & 209 \\
\hline Fin stiffener (ID:2) & 370 & 419 & 205 \\
\hline Fin stiffener (ID:4) & 230 & 326 & 207 \\
\hline
\end{tabular}

Table 3: Mechanical properties of steel members.

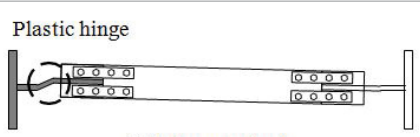

(a) Failure mode A

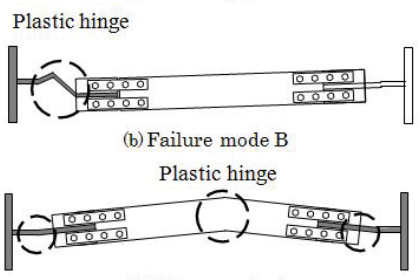

(c) Failure mode C

Figure 9: Failure modes on ultimate state.

8), the thickness of gusset plate, and the repair state is assumed whether the damaged test specimen is repaired or not repaired, and the usage of side stiffener.

The thickness of gusset plate (SS400, grade of JIS standard) is prepared with $6 \mathrm{~mm}, 9 \mathrm{~mm}$. The slenderness ratio of brace member (SS400, grade of JIS standard) is 14,23.

The lists of test specimens, brace members, mechanical properties of materials are summarized in Tables 1-3.

\section{Measurement}

Test specimens were instrumented with sensors for measuring below items: vertical displacement, in/out of plane deformation of brace, out of plane deformation of gusset plate. And the vertical load is measured by load cell of loading machine. Strain of brace is measured at the $100 \mathrm{~mm}, 25 \mathrm{~mm}, 315 \mathrm{~mm}$ from the end of brace by strain gauge.

\section{Test Results and Considerations}

\section{Results of initial loading test}

During loading test, 3 kinds of failure modes were observed as shown in Figure 9. The relation of axial force $\mathrm{N}$-axial displacement $\delta$ curves of monotonic loading test are shown in Figure 10. Table 4 comparers the test results of original and repaired test specimen.

H-6-95-S specimen: In case of H-6-95-S as shown in Figure 10a, according to the results of strain, the brace member remained within elastic range. From the ultimate state of test specimen, the plastic failure

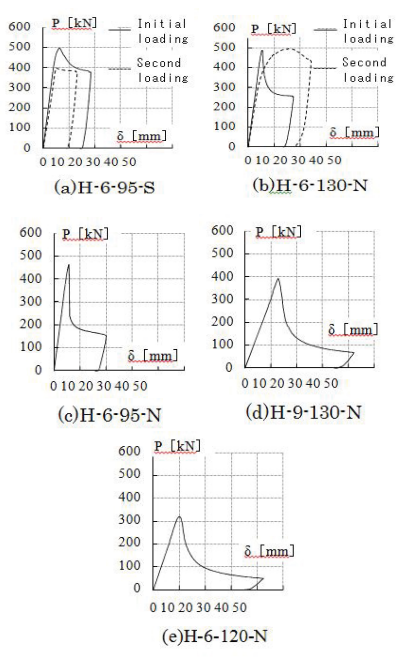

Figure 10 a-e: Loading test result. 


\begin{tabular}{|c|c|c|c|c|}
\multicolumn{2}{|c|}{ Specimen } & $\begin{array}{c}\text { Initial rigidity } \\
\mathbf{( k N / m m )}\end{array}$ & $\begin{array}{c}\text { Maximum } \\
\text { load (Kn) }\end{array}$ & $\begin{array}{c}\text { Stable } \\
\text { strength (kN) }\end{array}$ \\
\hline \multirow{2}{*}{ H-6-95-S } & Initial loading test & 99 & 497.54 & 378 \\
\cline { 2 - 5 } & Second loading test & 77.2 & 398.42 & 380 \\
\hline H-9-130-N & Initial loading test & 30 & 392.35 & 55 \\
\hline \multirow{2}{*}{ H-6-130-N } & Second loading test & 87.8 & 488.84 & 255 \\
\cline { 2 - 5 } & Initial loading test & 82 & 495.92 & - \\
\hline H-6-120-N & Second loading test & 33.3 & 321.14 & 40 \\
\hline H-6-95-N & Initial loading test & 95.4 & 163.72 & 150 \\
\hline
\end{tabular}

Table 4: Experimental result.

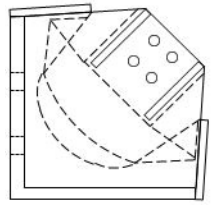

(a) $\mathrm{H}-6-95-\mathrm{S}$

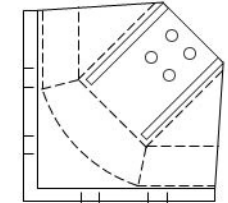

(b)H-6-95-N(Initial loading) (b)H-6-95-N(Second loading)

Figure 11: The result of deformation (Yield line)

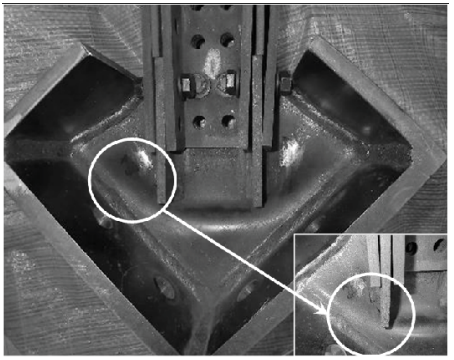

Figure 12: Caused clacks.

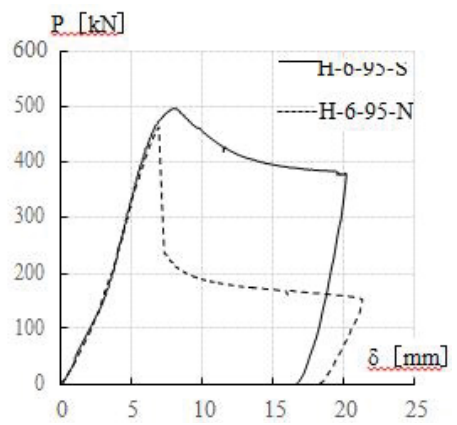

Figure 13: Comparison between reinforce existence and non.

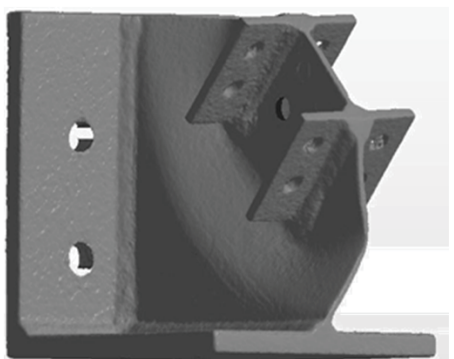

Figure 14: 3D model of damaged test.

mechanism was formed by occurrence of three plastic hinges on gusset plate (herein after referred to as "failure mode B"). And also, the out of plane deformation on gusset plate was observed too.
H-6-120-N and H-9-130-N specimen: In case of H-6-120-S and H-9-130-N as shown in Figures $10 \mathrm{~b}$ and $10 \mathrm{c}$ from the ultimate states of test specimen, the plastic failure mechanism was formed by occurrence of one plastic hinges on brace member, and both joint end behaved as pin (herein after referred to as "failure mode C"). And also, the out of plane deformation on gusset plate was observed too.

H-6-120-N and H-9-130-N specimen: In case of H-6-120-S and H-9-130-N as shown in Figures 10d and 10e, from the ultimate states of test specimen, the plastic failure mechanism was formed by occurrence of one plastic hinges on brace member, and both joint end behaved as pin (herein after referred to as "failure mode C"). And also, the out of plane deformation on gusset plate was observed too.

Ultimate state and repair method on damaged test specimen: From the ultimate state of test specimens, the plastic failure mechanism and yield lines were summarized in Figure 11. In cases of H-6-95-N, H-6$120-\mathrm{N}$ and $\mathrm{H}-9-130-\mathrm{N}$ specimens, the excessive plastic deformations were generated, so it was decided that they cannot be adopted by repair method as previous mentioned on section 1.1.

\section{Results of second loading test}

H-6-95-S specimen: In case of H-6-95-S, from the ultimate state under first loading, this damaged test specimen was not restored from the second loading test, the plastic deformation of gusset plate was progressed with same as initial loading test. From the comparison of test result of first loading and second loading, the maximum load reached $80 \%$ of initial loading test, and initial rigidity became $76 \%$ of initial loading test.

H-6-130-N specimen: In case of H-6-130-N, the damaged test specimen was repaired. From the second loading test, a crack was observed on gusset plate around weld part of fin stiffener as shown in Figure 12, however, the side stiffener did not yield.

From the comparison of test result of first loading and second loading, the maximum load presented almost same with initial loading test. The restoring force characteristics after repair related to load and displacement curve became bigger.

\section{Consideration of test results and repair effect}

Effect of side stiffener after repair: The comparison of test results of repaired specimen with side stiffener and repaired specimen without side stiffener is shown in Figure 13. From the comparison of Figure 13 , it can be confirmed that initial stiffness presents almost same, however, the maximum load increase about $10 \%$ by using side stiffener. Moreover, it can be confirm that stable strength after buckling increase about 2.5 times.

From the above observations, the side stiffener as repair member can prevent the rapid deterioration of load carrying capacity after buckling, and also it can reinforce the absorbed energy capacity. Regarding H-6$130-\mathrm{N}$ specimen, it can be confirmed that maximum load reaches almost same as original state. Moreover, out-of-plane deformation of gusset plate is restricted and converge deformation in gusset plate.

Absorbed energy capacity: In case of H-6-130-N specimen after repair, from the comparison of restoring force curve of test results, it is confirmed that the absorbed energy capacity until maximum load increase by 3.9 times to original state. It is thought that some replaced splice plate and internal gusset plate can absorb the plastic energy. From the observation of loading test, it is confirmed that the cracks on gusset plate around weld part of fin stiffener and new two yield lines were generated, and it means that the plastic deformations were occurred, and it contributed to absorb the plastic energy. 


\section{Discussion}

\section{D-modeling and analytical study of plastic limit analysis of damaged gusset plate}

From the ultimate states of test results above mentioned, the large plastic deformation was observed on gusset plate during first loading and second loading test. In addition, these plastic behavior effects the resistant mechanism of steel braced member on original and repaired state.

Sometimes, such plastic deformation of plate presents complicated shape and figure, and it is also very difficult to predict the complicated deformation and yield lines related to failure mode. Furthermore, the ultimate state of resistant performance can be calculated by limit analysis, however, it is not easy to assume the analytical model above mentioned.

Herein, the plastic deformation of test results is measured by 3D-scan, and 3D model is made by analysis. Finally, the analytical model of limit analysis is composed, and the ultimate state is predicted analytically.

\section{D-modeling method and technique}

The ultimate state of damaged gusset plate after plastic deformation is measured and converted into 3D data by "Photo Scan". For example, the 3D model of H-6-95-N specimen is described in Figure 14. The 3D-model is made by 180 photo data which are taken from deferent heights and 360 degrees. Also, "Auto desk Netfabb Standard2017" and "ArtecStudio9" is used for measuring 3D model.

\section{Outline of 3D model and analytical model of limit analysis}

From the result of 3D-model of damaged test specimen, the relation of analytical model on limit analysis is assumed. The example of H-695-N specimen is described in Figure 15.

From the viewpoint of limit analysis, the relation of plastic deformation is obtained from 3D-model, and the constants and variables on limit analytical model are defined as shown in Figure 15. It is assumed that rotational angle of plastic hinge on yield line maintain the ratio $1: 4$ based on result of $3 \mathrm{D}$ measuring.

\section{Mechanical study}

The analytical model of brace member is presented in Figure 15, the horizontal displacement $(\Delta u)$ of steel frame with brace and the vertical displacement $(\Delta v)$ of brace member and gusset plate are calculated by following equations (1) and (2).

$$
\begin{aligned}
& \Delta u=L-l_{1}-l_{2} \cos 4 \theta-l_{3} \cos \theta \\
& \Delta v=l_{2} \cos 4 \theta-l_{3} \sin \theta
\end{aligned}
$$

Deform the equation (3),

$$
\cos \theta=-\frac{1}{2} \sqrt{(A+B)}+\frac{1}{2} \sqrt{\left(C-B+\frac{l_{3}}{\left(4 l_{2} \sqrt{A-B}\right)}\right)}
$$

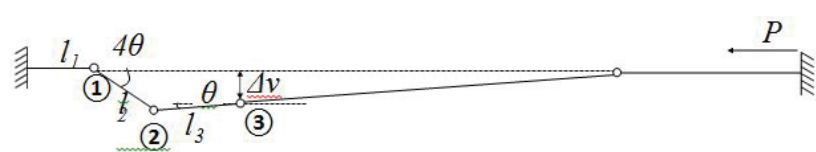

G.PL Brace $\cdots \quad$ G.PL

Figure 15: Limit analysis model ( $\mathrm{H}-6-95-\mathrm{N})$.

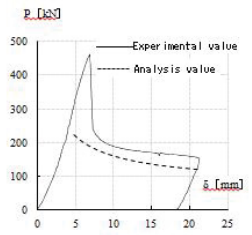

(a) $\mathrm{H}-6-95-\mathrm{N}$

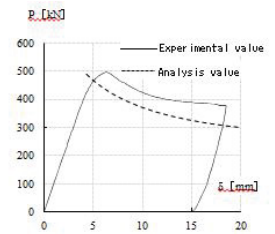

(b) $\mathrm{H}-6-95-\mathrm{S}$

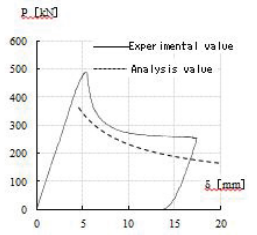

(c) H-6-130-N
Figure 16: Comparison between test results and analytical results.

Herein,

$$
\begin{aligned}
& A=\frac{2}{3}+\frac{a}{\left\{3(b+c)^{\frac{1}{3}}\right\}} \\
& B=\frac{(b+c)^{\frac{1}{3}}}{d} \\
& \mathrm{C}=\frac{3}{4}-\frac{a}{\left\{3(b+c)^{\frac{1}{3}}\right\}} \\
& a=4 \times 2^{\frac{1}{3}}\left(2 l_{2}^{2}-3 l_{2} l_{3}+3 l_{2} \Delta \mathrm{u}\right) \\
& b=-1024 l_{2}^{3}+216 l_{2} l_{3}^{2}+4608 l_{2}^{2}\left(-l_{3}+\Delta \mathrm{u}\right) \\
& c=-4\left(64 l_{2}^{3}-96 l_{2} l_{3}+96 l_{2} \Delta u\right) \\
& d=\frac{1}{24} \times 2^{\frac{1}{3}} l_{2}
\end{aligned}
$$

The relationship between $\Delta \mathrm{u}$ and $\Delta \mathrm{v}$ can be expressed as shown in equation (3),

$$
\Delta v=\sqrt{1-\cos ^{2} \theta}\left[4 l_{2} \cos \theta\left\{-2\left(1-\cos ^{2} \theta\right)+1\right\}-l_{3}\right]
$$

From equation of eccentric moment and full plastic moment related to yield line on gusset plate, the following relation is derived.

$$
P=\frac{\sum M_{p}}{\Delta v}
$$

Herein, Mp: full plastic moment of gusset plate.

Figure 16 compares the load-displacement curve of analytical results and test results during ultimate state. From the comparison of Figure 10, it can be confirmed that the analytical model can chase the test results well.

\section{Conclusion}

This paper focused on repair methods for damaged steel brace members and suggest mechanical model used 3D model. The main conclusion is shown below:

1. It is reproduced that damage case which arise local bending deflection on gusset plate by vertical loading test and reveal its collapse state. 
Citation: Yasuto Y, Aoki K, Ito T, Choi C (2017) Study on Ultimate State and Mechanical Characteristics of Connection Joint of Damaged H-Shaped Bracing Structure. J Civil Environ Eng 7: 286. doi: 10.4172/2165-784X.1000286

Page 6 of 6

2. Using side stiffener as reinforce member check deteriorating load after plastic and increase absorption plastic energy.

3. Using side stiffener as repair member check out- of-plane deformation of gusset plate and keep maximum load almost same as original state.

4. It is suggested mechanical model relate with hysteresis characteristics in deterioration area based 3D data and evaluate the trend after plasticized.

\section{Acknowledgement}

This research was supported by Grand-in-aid for Scientific Research (C) in Japan (Head: Takumi Ito).

\section{References}

1. Disaster Prevention Association (2015) The Japan building Disaster Prevention Association Technical manual. Japan. p. 12

2. Disaster Prevention Association (1998) The Japan Building Disaster Prevention Association: Post-Earthquake Temporary Risk Evaluation of Damaged Building. Japan. p. 1.

3. Research and Development Consortium (2013) A study of steel building adopted box column with brace (Annual report). p. 3 . 